Article

\title{
Study of differences in motor reactions and performances in professional ice hockey players and not experienced participants using virtual reality (VR) technology
}

\author{
Irina Polikanova ${ }^{1,3^{*}}$, Anastasiya Yakushina ${ }^{1}$, Sergey Leonov ${ }^{{ }^{*}}$, Anastasiya Yavorovskaya ${ }^{1}$, Anna \\ Kruchinina ${ }^{2}$, Victor Chertopolokhov ${ }^{2}$ and Liudmila Liutsko ${ }^{1^{*}}$ \\ 1 Faculty of Psychology, Lomonosov Moscow State University, Moscow 125009, Russia; \\ anastasiushka96@yandex.ru (A.Yak.); yavorovskaya97@gmail.com (A.Yav.) \\ 2 Faculty of Mechanics and Mathematics, Lomonosov Moscow State University, Moscow 119991, Russia; \\ anna.kruchinina@math.msu.ru (A.K.); psvr.msu@gmail.com (V.C.) \\ 3 Faculty of Biology and Biotechnology, HSE University, Moscow 101000, Russia \\ * Correspondence: irinapolikanova@mail.ru (I.P.), Tel.: +7-905-504-65-49; svleonov@gmail.com (S.L.); \\ liudmila_liutsko@yahoo.es (L.L.)
}

\begin{abstract}
The efficiency of performance in various sports has the development of certain specific skills at its core. In ice hockey, both the technical aspects (techniques, stance) and the cognitive ones (keeping attention on the puck, game strategy, etc.) are highly important. This study is aimed at the identification of specific features that determine the performance efficiency of professional hockey players. We used virtual reality (VR) to study the differences between professional ice hockey players and novices in terms of motor responses to the puck's presentation on different levels of difficulty. The study involved 22 participants, 13 of them being professional ice hockey players $\left(\mathrm{Mage}_{\mathrm{a}}=20 \pm 2.9\right.$; mean age of training experience $\mathrm{M}=14.18 \pm 3.8$ ) and 9 being not experienced participants $(\mathrm{Mage}=20 \pm 1.4)$. The study showed that the stick response time of professional hockey players is significantly higher $(0.98 \mathrm{~ms}$ vs $1.5 \mathrm{~ms}, \mathrm{p} \leq 0.05)$ in more difficult situations close to a real game. Moreover, professionals proved to have more stable movement patterns of the knee and hip joints. They also make fewer head movements as a response to stimuli during all runs $(0.66$ vs $1.25, p \leq 0.05)$. Therefore, the results indicate specific spatial-temporal, technical and tactical, and energetic determinants, that ensure higher performance efficiency in hockey players
\end{abstract}

Keywords: virtual reality, VR, hockey training, motor reaction, response time, sport

\section{Introduction}

Virtual reality (VR) is a complex system combining advanced technologies and high-quality graphics, which allows to immerse a person into the realistic virtual environment [1]. As the literature analysis showed, VR is often understood as one of the three types of systems: virtual environment (VE), presented on a flat screen, head-up display/HMD helmet or virtual environment that fills the whole room (such as the $\mathrm{CAVE}^{1}$ system) [2]. Despite the differences between the systems, they all have one common feature, which is a stereoscopic depth that creates a sense of deep immersion into the virtual environment. Over the past 20 years, this technology has been actively used in experimental and diagnostic studies [2] in neuropsychology, social psychology, cognitive psychology as well as in psychology of sport [3]. VR has now been particularly used in diagnostics and rehabilitation for the most effective and quick recovery of athletes' physical abilities and their

${ }^{1}$ Cave Automatic Virtual Environment 
psychological well-being [4;5]. It has also been introduced into the training process of athletes to develop and improve their sport skills [6].

VR has a number of advantages over the classic experimental methods of psychology. This technology has a high level of ecological validity [3; 7], allows to control the attention of a participant [7; 2; 3], set various stimuli parameters, including polymodal stimulation [3], simulate unique experimental conditions. Moreover, the participant can receive a real-time feedback.

\subsection{Development and improvement of sport skills using VR technology}

Over the last decade, the VR technology has been actively used to develop, train and improve sport skills $[1 ; 8 ; 9]$. It is important to maintain certain conditions to use VR most effectively. First, the environment created by the researcher shall fully and clearly reflect reality; secondly, the athlete shall make decisions based on the data obtained in reality; and thirdly, the athlete shall be able to interact with the environment [8]. It should also be noted that while developing a new skill, the virtual environment cannot be modified, i.e. the training should be done under the same conditions until the skill is reinforced [8], the conditions are to be changed after that.

VR allows to practice movements with no damage to the health of athletes since the risk of injury is reduced. VR can also help train the athlete's cognitive functions required for a high performance (for example, attention allocation, long-term memory etc.). Furthermore, VR provides the opportunity to train under conditions beyond athlete's capacities in real environment. To master and reinforce their skills, it is important that in VR athletes act the same as it is expected of them in reality [1]. The skills should be practiced under various conditions, otherwise the required performance would be achieved under the set conditions only [1]. The athlete shall receive an adequate timely feedback, which in turn facilitates better cognitive, perceptual, and motor tasks performance [1].

Sport skills training in VR has a number of advantages. The researcher can fully simulate the required training situation, for example manipulate the weather in virtual environment (to achieve athlete's psychological stability to various climatic conditions), set the required game experiences (such as ball speed, serve angle, force, gravity, etc.), put the athlete in front of any other player (such as a favorite athlete or, on the contrary, the athlete's opponent) [9]. Moreover, the simulated environment allows to monitor athlete's progress more effectively and is a high-quality diagnostic tool.

\subsection{Distinctive features of hockey training}

Ice hockey is a team sport on ice, the main goal of which is to put the puck in the opponent team's net more times than the opponent does at the specified time. The team that scores more goals wins. High muscular load and work intensity with maximum performance for a certain period are typical of hockey [10]. In order for hockey players to withstand such loads long enough, their endurance and muscular strength should be increased [11]. Thus, there is a need for regular tests to diagnose and monitor athletes' indicators [12]. Skating skills are also of a high significance for hockey players. The most distinctive skill indicators are maximum skating speed, reaction time and coordination of movements, which serves to distinguish between professional players and novices [13-16]. Therefore, training and developing of these skills can improve indicators and increase performance of the 
athletes during competition [17]. In this regard, various methods and techniques can be used to elevate the quality of training and improve the performance of athletes. For example, Blanár \& colleagues [18] in their research used exercises for dynamic balance and maximum load on lower limbs (standing long jumps, high jumps, one-legged jumps, etc.). It showed that the indicators of the explosive strength of lower limbs and ability to keep balance have impact on athletes' exercising and skating. It was demonstrated, that the better these parameters are developed, the more successful the athlete does exercise [18]. So, the development of dynamic balance and strength of lower limbs will accordingly enhance the athlete's performance. A special program called Hockey Canada Skills Test (HCST) was developed in Canada to measure sport-specific ice skills of youth hockey players aimed at improving each player's performance based on individual feedback on each testing. This feedback allows to further enhance the skills required for playing hockey successfully [19]. Aside from that, the integral part of hockey training is psychological preparation, especially athletes' cognitive functions. The cognitive processes of hockey players face special requirements during the game: vast amount of signals that incorporate important information, their dynamicity and variability; high dynamicity of sensory field; rapid signal representation; time restrictions in performing game operations; intermittency of perception and motor responses; persistent immunity to irrelevant stimuli and distractor stimuli; constant search for optimum tactical solutions with a growing tiredness in the background [20]. There are therefore many factors that influence the efficiency of the players' actions. In this regard, it seems to be important that, apart from the given methods of diagnostic and skills development, a specialized environment for skills training is created with the help of VR. For example, the research of Buns [21] based on the idea that virtual training is an effective tool to enhance sport skills, showed that hockey training in virtual environment has an impact on the real-world training efficiency. Compared to the control group, the members of the experimental group, significantly increased the accuracy and speed of their shots on goal [21]. The research of Tyreman and colleagues [15] also demonstrated that in a simulated three-dimensional environment the reaction time of professional ice hockey goaltenders does not differ from the one of the novices. However, a special type of shot was discovered that was typical of the professionals only. That is, it was a detailed comparative analysis of indicators obtained by means of three-dimensional space that made it possible to determine the differences between professional goaltenders [15]. The efficiency of virtual reality technologies has been repeatedly demonstrated both in educational and sports activities [22; 23; 9], but there is basically no research on the improvement of hockey skills. In this regard, we think it is important to set up a specialized virtual space to diagnose and develop hockey skills. The developed approach is based on the athletes' ability to train the perception and sensation of microintervals of time and acceleration of their reaction time, as well as training to control their motor reactions depending on the task. Such system shall allow to identify the movement patterns of eye and body attributed to professional hockey players and prepare further training for youth hockey players and novices so that they can acquire new skills and improve their performance. As a result, VR training can serve as an auxiliary stage in the development and training of athletes' skills, which 
shall make early-stage training processes safer, and also avoid the feel of monotony. In addition, virtual reality system enables us to compare the movement patterns of professional hockey players and those of the novices. Any sport is determined by specific factors that may reflect the degree of proficiency [24]. Our analysis showed that in order for professional hockey players to be effective in their activity, they shall develop specific skills associated with certain factors, or determinants. These factors include, for example, spatial-temporal and technical and tactical abilities [25]. This is primarily connected with the abundance and speed of sensory and information flows and the need to swiftly analyze the situation on the rink and make decisions, as well as the speed of motor reactions and their further automatization. Hockey is also an energetically intensive sport, so the motor skills should be developed with the maximum optimization of resources. Thus, we may conclude that such factors, or determinants, as spatial-temporal and technical and tactical abilities, as well as the energy factor are of a high importance for the activity of a professional hockey player. This study is aimed at stating how well-developed the skills of the professional hockey players are in comparison with the ones of novices, and emphasizing the motor distinctive features of professionals using a specially created virtual environment.

\section{Materials and Methods}

\subsection{Participants}

Twenty-two athletes participated in the study $\left(\mathrm{Mage}_{\mathrm{ag}}=20, \mathrm{SD}_{\mathrm{age}}=2.3 ; 100 \% \mathrm{men}\right) ; 13$ of them being professional ice hockey players (group "hockey") $\left(\mathrm{Mage}_{1}=20, \mathrm{SD}_{\mathrm{age}}=2.9\right.$; mean age of their training experience $\mathrm{M}=14.18, \mathrm{SD}=3.8$ ) and 9 being not experienced participants ( $\mathrm{M}_{\mathrm{age}}=20, \mathrm{SD}_{\mathrm{age}}=1.4$ ). It should be noted that not experienced participants, group "novice", also consisted of athletes, freestyle wrestlers mostly (out of 9 subjects, 7 were freestyle wrestlers or other combat sports (from 1.5 to 12 years of experience), 1 subject was a motocross racer (5 years of experience), 1 subject was a trampolinist (17 years of experience)).

All of them participated on a voluntary basis with the previously signed consent, already approved by the Ethical Committee of the Russian Psychological Society (03/2021).

\subsection{Tools, instruments and programmes}

For the study, a special virtual stage was developed in the Unity system, which displays the environment from the point of view of a hockey player standing on the goal line (Fig. 1 \& Fig. 2). The subject views the body of his virtual avatar in the first-person and hold a stick (the stick in the virtual environment is the same as in reality). There are no other players on the rink. The player's equipment corresponds to that of a field player. The player is instructed as follows: hit all the pucks flying into the net with a stick. Pucks are presented randomly from various distances and directions and with different initial speeds. Each puck starts with a specific click sound. Just before the puck is presented, the rink section from which the puck starts, is illuminated with yellow light (Fig. 3). Pucks that were hit not with a stick do not count. The simulation of pucks shooting includes three blocks of difficulty depending on the speed of the pucks and their distance from the subject. The closer the distance and the higher the speed, the more difficult the block is. Block 1 is the simpliest, with low puck speeds $(60-80 \mathrm{~km} / \mathrm{h})$ and long distances to the puck $(18 \mathrm{~m})$, so even beginners with no hockey experience would manage to hit. Block 2 is more difficult, speeds are higher $(60-80 \mathrm{~km} / \mathrm{h}$, and $100 \mathrm{~km} / \mathrm{h})$, average 
distances to the puck are longer (12 and $18 \mathrm{~m})$. Block 3 is for medium skill level; it's a difficult mode with high speeds (up to $170 \mathrm{~km} / \mathrm{h}$ ) and all distances, including close ones $(6,12,18 \mathrm{~m}$ ). Block 4 is the most difficult one, where the pucks are presented in a series of two (in sequence with a $1 \mathrm{~s}$ interval). Block 5 is where the subject is not supposed to hit the pucks, but only carefully watch and track the pucks, which are presented with a random difficulty. Interval between the pucks is $3 \mathrm{~s}$ with a click sound. After each puck, the player looks to the center. The results of the block 5 were not considered in this article.

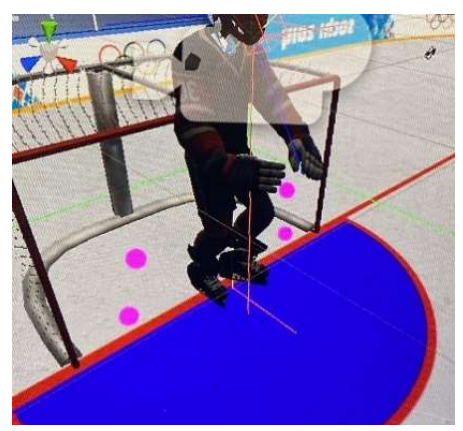

Figure 1. Avatar

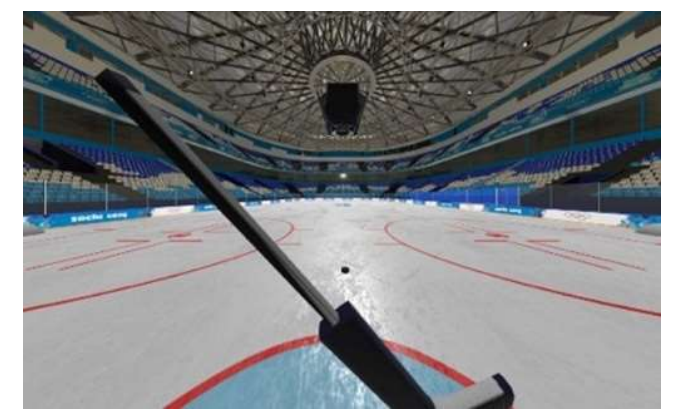

Figure 2. Environment visualization in VR helmet

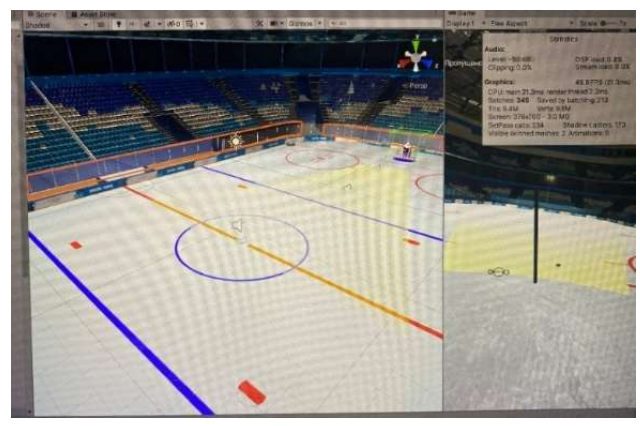

Figure 3. Rink section illumination (general view on the left, view in front of the subject on the right)

\subsection{Analyzed parameters}

The movements of the subject's body parts, and the stick were registered using SteamVR Tracking 2.0 system. Trackers were attached to the shin guards, hips, chest, gloves, and stick (Fig. 4). The changes in the angles in knee and hip joints were chosen to be analyzed. To fully evaluate the stance and mistakes, we considered the relative position of trackers on the right and left hips, alongside with the tracker of the head position (tracked by VR helmet) in relation to the legs.

To analyze the motor reaction, the following parameters were selected: changes in the angle in the knee joint (right and left knee); changes in the angle in the hip joint (right and left side); stick movement (average speed per measurement cycle); the speed of reaction to pucks presentation. The VR technology that we developed allows to register the number of hitting and missed pucks, the subjects' reaction time, and the moments of section illumination and pucks arrival.

For these values, it was calculated as follows: time window is $0.1 \mathrm{~s}$, the moments of motor reaction were selected as peaks having a greater height than tripled value of the mean-square deviation of the corresponding value during a still standing (30 s before stimuli). 


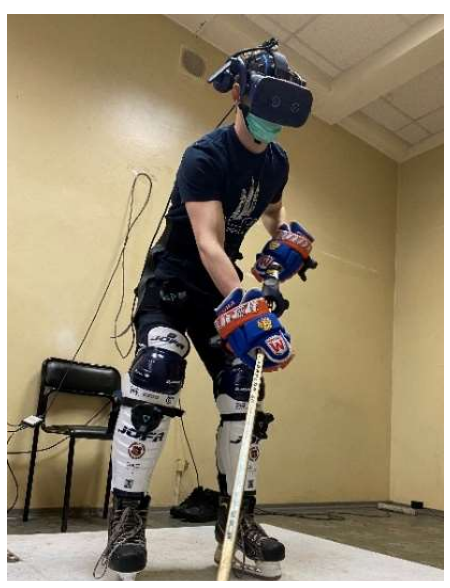

Figure 4. Subject with the trackers attached to his shin guards, hips, chest, gloves and stick

\subsection{Data analysis}

Statistica 8 (for Windows, V 8.0, StatSoft) was used for statistical data analysis. A nonparametric Mann-Whitney criterion was used to compare a group of hockey players and a group of novices (not hockey players).

For statistical analysis, the following parameters were calculated:

- hitting and missed pucks,

- motor response time to puck's arrival (RT1),

- stick response time (RT2).

\section{Results}

\subsection{Value of hitting pucks}

The analysis revealed significant differences between the groups of hockey players and novices in the number of missed pucks in the third block, where the fastest pucks were presented - up to 170 $\mathrm{km} / \mathrm{h}(9.00$ vs $10.56, \mathrm{p}=0.51)$. The number of hitting and missing pucks are reciprocal, however in terms of the number of hitting pucks, the differences between the groups are observed only at the trend level (4.85 vs 3.44, $\mathrm{p}=0.06$ ) (Table 1 ).

Table 1. Average values of hitting and missed pucks

\begin{tabular}{|c|c|c|c|c|c|c|c|c|}
\hline \multirow[t]{2}{*}{ Group } & \multicolumn{4}{|c|}{ Hitting pucks } & \multicolumn{4}{|c|}{ Missed pucks } \\
\hline & block 1 & block 2 & block 3 & block 4 & block 1 & block 2 & block 3 & block 4 \\
\hline Hockey & $7.77 \pm 2.9$ & $5.85 \pm 1.7$ & $4.85 \pm 1.7$ & $8.00 \pm 2.3$ & $6.54 \pm 2.9$ & $8.00 \pm 1.6$ & $9.00 \pm 1.7$ & $20.91 \pm 2.3$ \\
\hline Novice & $6.63 \pm 3.2$ & $5.56 \pm 2.6$ & $3.44 \pm 1.9$ & $7.44 \pm 1.8$ & $7.13 \pm 3.1$ & $8.56 \pm 1.6$ & $10.56 \pm 1.9$ & $22.11 \pm 3.2$ \\
\hline $\begin{array}{c}p-\text { Value for } \\
M-W \text { criterion }\end{array}$ & 0.374 & 0.601 & 0.060 & 0.656 & 0.595 & 0.471 & $0.051^{*}$ & 0.503 \\
\hline Cohen's d & 0.40 & 0.13 & 0.78 & 0.27 & 0.20 & 0.35 & 0.86 & 0.43 \\
\hline
\end{tabular}

\subsection{Response time}

The results showed significant differences in the stick-to-puck response time in block 4 (sequential presentation of 2 pucks with $\Delta 1 \mathrm{sec}$, RT2) (0.98 vs 1.50, p=0.02) (Table 2). No significant differences 
in motor responses to the introduction of stimulus (RT1) were revealed, that means that the motor response to the stimulus is approximatey the same in the group of hockey players and novices.

Table 2. Average values of motor response time (RT1) and stick response time (RT2), sec (M+SD).

\begin{tabular}{|c|c|c|c|c|c|c|c|c|}
\hline \multirow[t]{2}{*}{ Group } & \multicolumn{4}{|c|}{ RT1 } & \multicolumn{4}{|c|}{ RT2 } \\
\hline & block 1 & block 2 & block 3 & block 4 & block 1 & block 2 & block 3 & block 4 \\
\hline Hockey & $0.44 \pm 0.15$ & $0.41 \pm 0.14$ & $0.37 \pm 0.17$ & $0.29 \pm 0.07$ & $1.13 \pm 0.35$ & $0.96 \pm 0.42$ & $1.08 \pm 0.65$ & $0.98 \pm 0.30$ \\
\hline Novice & $0.38 \pm 0.19$ & $0.33 \pm 0.12$ & $0.31 \pm 0.08$ & $0.29 \pm 0.06$ & $1.58 \pm 0.73$ & $1.55 \pm 0.92$ & $1.66 \pm 1.54$ & $1.50 \pm 0.71$ \\
\hline $\begin{array}{c}p-\text { Value for } \\
M-W \text { criterion }\end{array}$ & 0.268 & 0.098 & 0.460 & 0.545 & 0.262 & 0.071 & 0.695 & $0.020^{*}$ \\
\hline Cohen's d & 0.35 & 0.62 & 0.45 & 0.00 & 0.79 & 0.83 & 0.49 & 0.96 \\
\hline
\end{tabular}

\subsection{Motor activity}

\subsubsection{Stance analisys}

One of the motor parameters that we analized was athlete's ability to maintain a hockey stance during the study. As a result we revealed significant differences between the hockey players and novices in maintaining the head's position $(p<0.025)$. Therefore the average head movement indicators of professional hockey players are lower than those of novices (Table 3 ).

Table 3. Average values of motor response time of different body parts, degree \pm SD.

\begin{tabular}{cccccc}
\hline Group & Knee, right & Knee, left & Hip, right & Hip, left & Head \\
\hline Hockey & $0.81 \pm 0.26$ & $0.77 \pm 0.26$ & $1.01 \pm 0.34$ & $1.13 \pm 0.34$ & $\mathbf{0 . 6 6 \pm 0 . 8 5}$ \\
Novice & $0.75 \pm 0.27$ & $0.72 \pm 0.22$ & $1.13 \pm 0.27$ & $1.13 \pm 0.22$ & $\mathbf{1 . 2 6 \pm 0 . 8 6}$ \\
$\begin{array}{c}\boldsymbol{p} \text {-Value for } \\
\text { M-W criterion }\end{array}$ & 0.346 & 0.628 & 0.456 & 0.722 & $\mathbf{0 . 0 2 5 ^ { * }}$ \\
Cohen's d & 0.25 & 0.21 & 0.37 & 0.02 & 0.70 \\
\hline
\end{tabular}

* level of statistical significance $p \leq 0,05$

\subsubsection{Movements analisys}

The study revealed significant differences between the groups of hockey players and novices in terms of the angles of inclination of knee and hip joints. Movement of professionals are proved to be more stable (Fig. 5 \& Fig. 6) than those of novices (Fig. 7 \& Fig. 8). This is reflected in the symmetrical and synchronous changes in the angles of knee and hip joints.

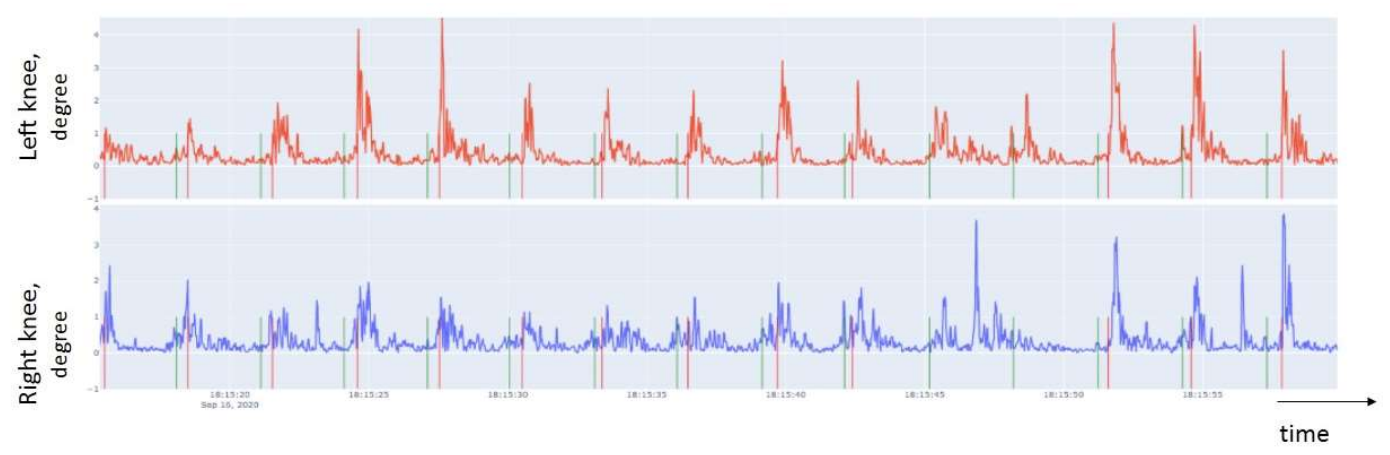

Figure 5. Change in the angle of the knee joint of professional ice hockey player (19 years of training experience) 


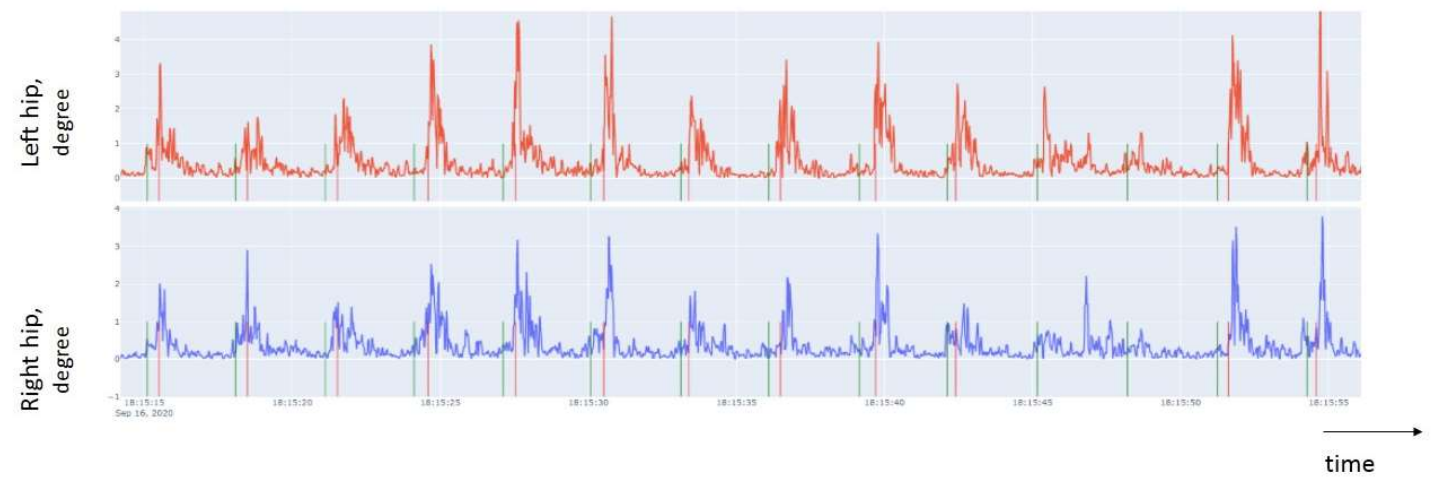

Figure 6. Change in the angle of the hip joint of professional ice hockey player (19 years of training experience)

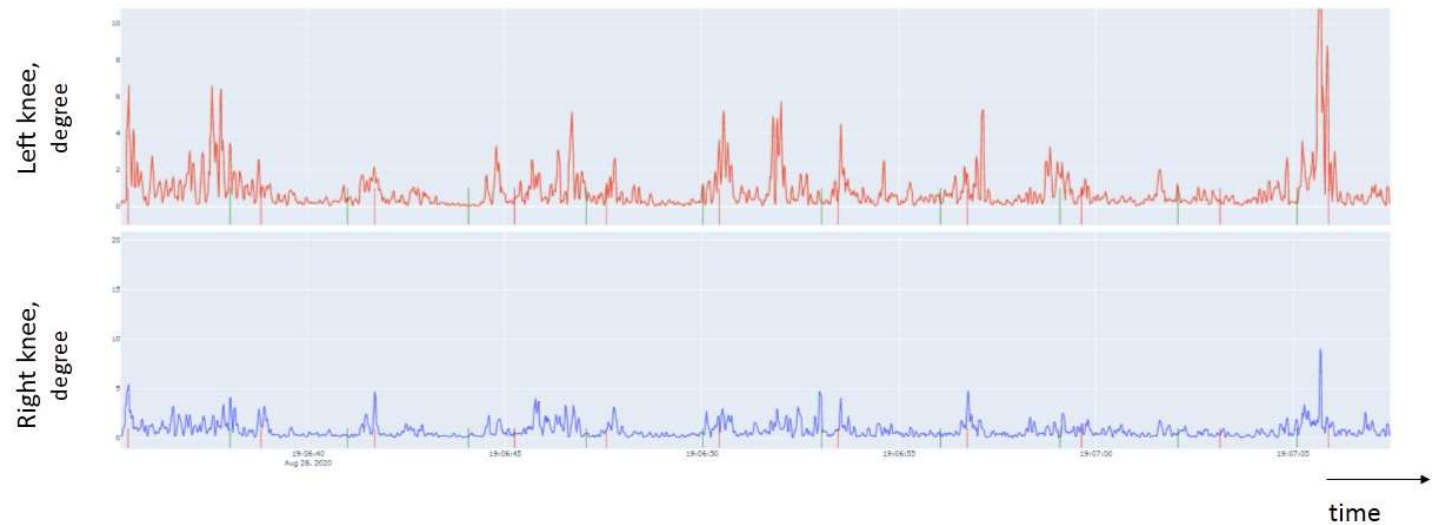

Figure 7. Change in the angle of the knee joint of not experienced participant

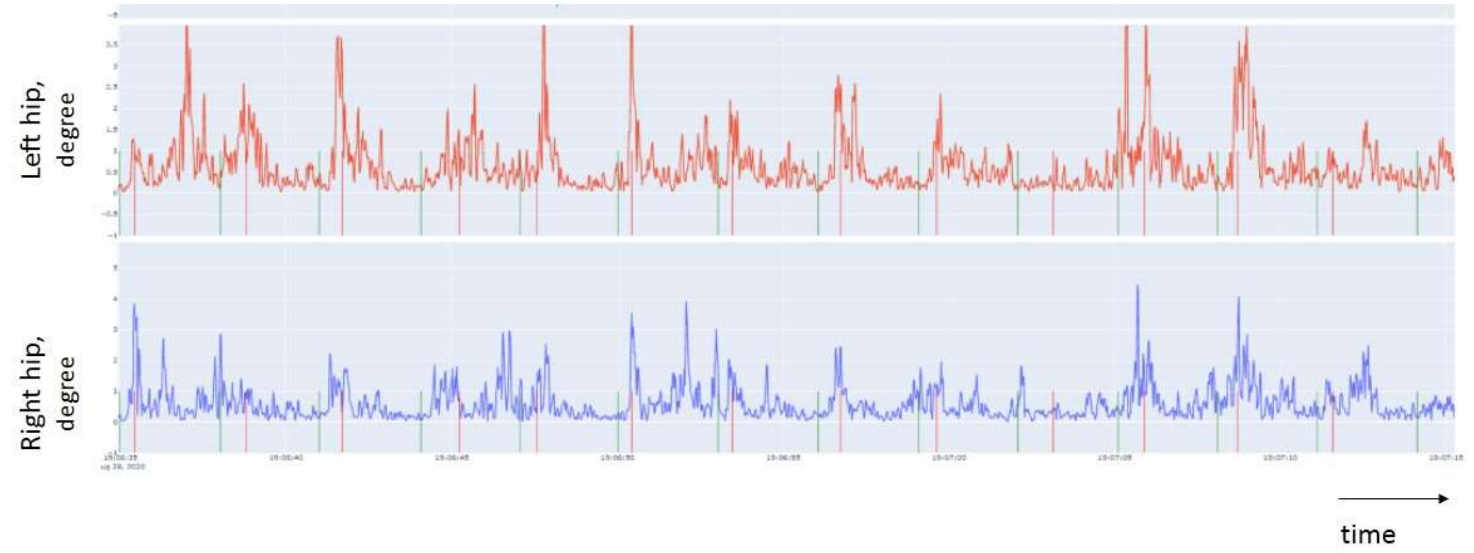

Figure 8. Change in the angle of the hip joint of not experienced participant

\section{Discussion}


The results demonstrated that professional ice hockey players showed better performance in pucks hitting compared to novices in the blocks with the highest puck speeds (block 3). This may be indicative of better spatial-temporal orientation, which allows to handle pucks hitting even under hard conditions (pucks speed was up to $170 \mathrm{~km} / \mathrm{h}$ - maximum hockey speeds). At the same time, the novice group showed a rather high efficiency level in pucks hitting. This may be due to the fact that the group novice consisted prevailingly of athletes (freestyle wrestlers), for whom the reaction time and anticipation are professionally important qualities. The ability to handle spatial situation well and swiftly react to opponent's actions is also essential for wrestlers [26]. We presume that the increase of participant's number and adding of a non-athlete group may allow to find significant differences in three groups of participants in terms of hitting and missed pucks.

In this study, we also analyzed the subjects' response time, which was divided into two separate parameters - response time to puck's arrival (RT1), and stick response time (RT2). RT1 was analyzed because it was important to see if professionals have specific technical, tactical and spatialtemporal factors, which would entail their greater efficiency. However, in terms of RT1, there were no differences between the groups. This means that the subjects in both groups did not differ in the rate of primary motor response to the pucks' presentation. In this case, the absence of differences may be associated with the good physical fitness of both groups.

Speaking of RT2, significant difference was revealed between the groups in block 4, which was marked by nearly simultaneous presentation of two pucks ( $\Delta 1 \mathrm{~s}$ between pucks). This might be tied to specific technical and tactical dominant developed by hockey players, which ensures better situation control and stick manipulation. We should note that the task of block 4 is more associated with a real game situation, since it is necessary to monitor several stimuli at the same time and manage to respond, which testifies that the temporal and spatial factors are well-developed. Moreover, athlete needs to make certain maneuvers here - motor skills with a stick to hit several pucks at once. Thus, the results obtained indicate that the spatial-temporal and technical-tactical abilities are well-developed in both groups. At the same time, hockey players possess a specific factor associated with technical and tactical and spatial-temporal abilities, which allows them to control the situation better and manipulate the stick to address complex tasks close to a real-game conditions in hockey.

The results also showed that, as opposed to novices, professional hockey players have higher and more stable fluctuations in movement indicators during the entire observation interval. This may be owing to the fact that professional hockey players have already developed a certain stable reaction to significant stimuli [27]. Moreover, professional players have distinct and stable movement patterns in response to the puck presentation, which may be indicative of resource input optimization [28; 29]. Therefore, we suggest that professionals have a better developed ability to optimize their resources to achieve the required results.

The professional hockey players also demonstrated a significantly lower amplitude of head oscillations during the study, which may mean that they have a well-developed spatial factor. It means they understand their body position quite well during certain actions, and do not need to fully follow the puck trajectory $[30,31]$. So, they keep their heads straight, do not lower them, which allows noticing the pucks more efficiently and faster than novices.

The results may imply that professional players have better developed technical and tactical abilities in comparison with novices, since when applying motor skills, they do not need to visually control the position of the body/stance or the puck. They try to look straight before themselves and control the moment when the puck is released.

As a result, we obtained the data that indicate differences in motor reactions (response time, efficiency of the puck hitting, stance maintaining) of the professional ice hockey players and not experienced participants. However, this study has a limitation - a small sample size. Since the study involved hockey players with a high level of sportsmanship ( $\mathrm{M}=14.2 \pm 2.3$ years of average hockey experience, range: 8-20 years old), access to whom is rather limited, especially given the coronavirus pandemic, the sample was not large in total. Moreover, each test recording took a rather long period of time due to the need of putting on hockey equipment, fixing the sensors and adjusting the VR 
equipment. It should also be noted that the group of not experienced participants also consisted of athletes - mostly freestyle wrestlers, which presumably had its impact on the results. For freestyle wrestlers, anticipation and response time are highly important, which could be the reason there was no significant difference in the puck hitting efficiency compared to hockey players. To check this assumption, we plan an additional research involving a group of non-athlete volunteers. We will then be able to supplement the obtained results and draw more objective conclusions. The results of this study are difficult to generalize to a broad sample. However, this is the first study that explores the use of virtual reality for the hockey performance indicators that might be important for a more efficient and effective training of future athletes.

\section{Conclusions}

The study resulted in finding significant differences between professional hockey players as opposed to novices in terms of the following indicators: response time to the rapidly presented pucks, ability to maintain a stable head position during response, and the presence of stable movement patterns.

Based on the data obtained, we concluded that professional hockey players have specific welldeveloped technical, tactical, energetic, and spatial-temporal determinants that allow a more efficient performance, which is expressly demonstrated in complex situations.

These results shall allow for further creation of a specialized training using a virtual reality system to improve the professional skills of hockey players.

\section{Supplementary Materials:}

Author Contributions: Conceptualization, I.P., S.L., L.L., A.K.; methodology, V.C., A.K., I.P. and L.L.; software, I.P. A.Yav. and A.Yak.; validation, I.P. A.Yav. and A.Yak.; formal analysis, A.Yav., A.Yak., S.L. and L.L.; investigation, A.Yav. A.Yak., I.P. and L.L.; resources, A.K., V.C., I.P. and L.L.; data curation, A.K., V.C., I.P. and L.L.; writing-original draft preparation, I.P., S.L. and L.L.; writing-review and editing, I.P., S.L. and L.L.; visualization, L.L.; supervision, S.L. and L.L.; project administration, S.L.; funding acquisition, S.L. All authors have read and agreed to the published version of the manuscript.

Funding: This research was funded by the Russian Science Foundation, grant number 19-78-10134.

Conflicts of Interest: The authors declare no conflict of interest. 


\section{References}

1. Farley, O.R.L., Spencer, K., \& Baudinet, L. Virtual reality in sports coaching, skill acquisition and application to surfing: A review. Journal of Human Sport and Exercise, 2020, 15(3), 535-548. doi:https://doi.org/10.14198/jhse.2020.153.06

2. Wilson CJ, Soranzo A. The Use of Virtual Reality in Psychology: A Case Study in Visual Perception. Comput Math Methods Med. 2015; 2015:151702. doi: 10.1155/2015/151702. Epub 2015 Aug 3. PMID: 26339281; PMCID: PMC4538594.

3. Zinchenko Yu. P., Menshikova G. Ya., Bayakovskii Yu. M., Chernorizov A. M., Voiskunsky A. E.(2010).Virtual reality technology in the context of world and national psychology: methodological aspects, achievements and prospects. National Psychological Journal, 2010, 1(3), 54-62

4. de Araújo A. V. L. et al. Efficacy of virtual reality rehabilitation after spinal cord injury: a systematic review //BioMed Research International, 2019, V 2019.

5. Gokeler, A., Bisschop, M., Myer, G.D. et al. Immersive virtual reality improves movement patterns in patients after ACL reconstruction: implications for enhanced criteria-based return-to-sport rehabilitation. Knee Surg Sports Traumatol Arthrosc, 2016, 24, 2280-2286 https://doi.org/10.1007/s00167-014$\underline{3374-x}$

6. Tsai W. L. et al. Improve the Decision-making Skill of Basketball Players by an Action-aware VR Training System //2019 IEEE Conference on Virtual Reality and 3D User Interfaces (VR)., IEEE, 2019, p. 1193-1194.

7. Charles Faure, Annabelle Limballe, Benoit Bideau \& Richard Kulpa Virtual reality to assess and train team ball sports performance: A scoping review, Journal of Sports Sciences, 2019 DOI: 10.1080/02640414.2019.1689807

8. Peter Le Noury, Tim Buszard, Machar Reid \& Damian Farrow Examining the representativeness of a virtual reality environment for simulation of tennis performance, Journal of Sports Sciences, 2020, DOI: 10.1080/02640414.2020.1823618

9. Song, P., Xu S., Fong, W. T., Chin C. L., Chua G. G., Huang Z.An Immersive VR System for Sports Education. IEICE Transactions on Information and Systems, 2012, E95.D(5), 1324-1331. doi:10.1587/transinf.E95.D.1324 (https://doi.org/10.1587/transinf.E95.D.1324)

10. Bishop, D., Lawrence, S., \& Spencer, M. Predictors of repeated sprint ability in elite female hockey players. J Sci Med Sport, 2003, 6(2), 199-209

11. Wilson, K., Snydmiller, G., Game, A., Quinney, A., \& Bell, G. The development and reliability of a repeated anaerobic cycling test in female ice hockey players. J Strength Cond Res, 2010, 24(2) 580-584

12. Power, A., Faught, B.E., Przysucha, E., Mcpherson, M., \& Montelpare, W. (2012). Establishing the test-retest reliability and concurrent validity for the Repeat Ice Skating Test (RIST) in adolescent male ice hockey players. Meas Phys Educ Exerc Sci, 2016, 16(1), 69-80

13. Marino, G.W. Selected mechanical factors associated with acceleration in ice skating. Res. Q. Exerc. Sport, 1983, 54(3), 234-238

14. Price, M. Simulated skating to enhance skating performance and leg power in elite hockey players. Undergraduate thesis, Acadia University, 2003

15. Tyreman, H., Parker, J. R., \& Katz, L. Ice hockey goaltenders' strategies, reaction times and anticipation times in two- and three-dimensional virtual enviroments. Proceedings of First Joint International PreOlympic Conference of Sports Science and Sports Engineering. Volume I: Computer Science in Sports., 2008, pp. 68-72.

16. Bracko, M.R. \& Fellingham G.W. Prediction of ice skating performance with off-ice testing in youth hockey players. Med. Sci. Sports Exerc, 1997, 29, 172.

17. Greer, N., Serfass, R., Picconatto, W., \& Blatherwick, J. The effects of a hockey-specific training program on performance of Bantam players. Can. J. Sport Sci, 1992, 17(1), 65-69.

18. Blanár, M., Brod’áni J., Czaková M., Kováčová N. Dependence of the skating and running performance from the explosive strength of lower limbs and dynamic balance of ice hockey players Sport Science, 2020, 1: 89-95

19. Eliason, P., McKay, C., Meeuwisse, W., Hagel, B., Nadeau, L., \& Emery, C. A. History of previous concussion and sports-specific skills in youth ice hockey players. Journal of Physical Education and Sport, 2020, 20(3), 2174 - 2181. [292]. https://doi.org/10.7752/jpes.2020.s3292

20. Novikov BI Experimental studies of the state of mental readiness of football players for the competition: Author's abstract. dis. ... doctor ped. Sciences, 1969. 
21. Buns M. Impact of Virtual RealityTraining on Real-World Hockey Skill: An Intervention Trial. Journal of Sports Science, 2020, 8-16 doi: 10.17265/2332-7839/2020.01.002

22. Ali S. F., Azmat S.A., Noor A.U., Siddiqui H. Noor S. Virtual reality as a tool for physical training 2017 First International Conference on Latest trends in Electrical Engineering and Computing Technologies (INTELLECT), Karachi, 2017, pp. 1-6, doi: 10.1109/INTELLECT.2017.8277617.

23. Isogawa, M., Mikami, D., Fukuda, T., Saijo, N., Takahashi, K., Kimata, H., \& Kashino, M. What Can VR Systems Tell Sports Players? Reaction-Based Analysis of Baseball Batters in Virtual and Real Worlds. 2018 IEEE Conference on Virtual Reality and 3D User Interfaces (VR). 2018, doi:10.1109/VR.2018.8446073 (https://doi.org/10.1109/VR.2018.8446073)

24. Polikanova, I., Leonov, S., Isaev, A., \& Liutsko, L. (2020). Individual features in the typology of the nervous system and the brain activity dynamics of freestyle wrestlers exposed to a strong physical activity (a pilot study). Behavioral Sciences, 10(4), 79

25. Tous Ral, J.M., \& Liutsko, L. (2014). Human errors: their psychophysical bases and the Proprioceptive Diagnosis of Temperament and Character (DP-TC) as a tool for measuring. Psychology in Russia: State of the art, $7(2)$.

26. Cvetkovic, C. Technical efficiency of wrestlers in relation to some anthropometric and motor variables /C. Cvetkovic, Y.Maric, N. Marelic // Kinesiology. 2005.-V. 37 (1). P. 74-83.

27. Savin V.P. Theory and methodology of hockey. M .: Publishing Center "Academy", 2003. - 400 p.

28. Sibirev V.V., Rodygina Yu.K. Psychophysiological characteristics of young hockey players during training. Theory and practice of physical culture, 2016, 9, 72-74.

29. Montgomery D.L. Physiology of ice hockey. Sports Med. 1988 Feb;5(2):99-126. doi: 10.2165/00007256198805020-00003

30. Behm, D. G., Wahl, M. J., Button, D. C., Power, K. E., \& Anderson, K. G. Relationship between hockey skating speed and selected performance measures. The Journal of Strength \& Conditioning Research, 2005, 19(2), 326-331.

31. Blanar, M., Brodani, J., Kovacova, N., Czakova, M., \& Siska,L. Limiting factors of skating performance in ice hockey. International Journal of Physiology, Nutrition and Physical Education, 2019, 4(1). 